\title{
Autogenous Tooth Transplantation from Ectopic Position: A Case Report and Review of Literature
}

\author{
MMR HOWLADER $^{\mathrm{a}}, \mathrm{S}_{\text {BEGUM }}^{\mathrm{b}}$, D NAULAKHA ${ }^{\mathrm{c}}$
}

\begin{abstract}
Summary:
Autogenous tooth transplantation, is the surgical movement of a tooth from one location in the mouth to another in the same individual. Once thought to be experimental, autotransplantation has achieved high success rates and is an excellent option for tooth replacement. Although the indications for autotransplantation are narrow, careful patient selection coupled with an appropriate technique can
\end{abstract}

\section{Introduction:}

One of the major breakthrough in medicine of the twentieth century was the ability to replace non functional kidney, liver, heart, lung or pancreas function through transplantation of a healthy organ. Although tooth transplantation began earlier, it was not very common in our routine dental practice.

The earliest reports of tooth transplantation involve slaves in ancient Egypt who were forced to give their teeth to their pharaohs ${ }^{1}$. However, allotransplantation transplantation of a tooth from one individual to another was eventually abandoned because of problems of histocompatibility and replaced with autotransplantation. Autogenous tooth transplantation, or autotransplantation is the surgical movement in one individual of a vital or endodontically treated tooth from its original location in the mouth to another site $^{2}$. Autogenous tooth transplantation was

a. Dr. Md. Mujibur Rahman Howlader, BDS, DDS, FCPS, MS, Associate Professor, Department of Conservative Dentistry and Endodontics, Faculty of Dentistry, Bangabandhu Sheikh Mujib Medical University, Shahbag, Dhaka.

b. Dr. Sharifa Begum, MS (Thesis) Student, Department of Conservative Dentistry and Endodontics, Faculty of Dentistry, BSMMU, Shahbag, Dhaka.

c. Dr. Deependra Naulakha, MS (thesis) Student, Department of Conservative Dentistry and Endodontics, Faculty of Dentistry, BSMMU, Shahbag, Dhaka.

Address of correspondence: Dr. Md. Mujibur Rahman Howlader, Associate Professor, Department of Conservative Dentistry and Endodontics, Faculty of Dentistry, BSMMU, Shahbag, Dhaka. lead to exceptional esthetic and functional results. One advantage of this procedure is that placement of an implant-supported prosthesis or other form of prosthetic tooth replacement is not needed. This article highlights the indications for autogenous tooth transplantation using one case report as example. Reviews of previous works as well as success rates are also discussed.

(J Bangladesh Coll Phys Surg 2006; 24: 79-85)

first well-documented in 1954 by M.L. Hale ${ }^{3}$. The major principles of his technique are still followed today. The science of autotransplantation has progressed, as evidenced by the high success rates reported in studies over the past decade. These studies demonstrate that autotransplantation is a viable option for tooth replacement for carefully selected patients.

While there are many reasons for autotransplanting teeth, tooth loss as a result of dental caries is the most common indication, especially when mandibular first molars are involved. First molars erupt early and are often heavily restored. Autotransplantation in this situation involves the removal of a third molar, which may then be transferred to the site of an unrestorable first molar. Other conditions in which transplantation can be considered include tooth agenesis especially of premolars and lateral incisors, traumatic tooth loss, atopic eruption of canines, root resorption, large endodontic lesions, cervical root fractures, localized juvenile periodontitis as well as other pathologies $2,9-$ 11. Successful transplantation depends on specific requirements of the patient, the donor tooth, and the recipient site.

\section{Candidate criteria:}

Patient selection is very much important for the success of autotransplantation. Candidates must be in good health, able to follow post-operative instructions, and available for follow-up visits. They 
should also demonstrate an acceptable level of oral hygiene and be amenable to regular dental care. Most importantly, the patients must have a suitable recipient site and donor tooth. Patient cooperation and comprehension are extremely important to ensure predictable results.

\section{Recipient site criteria:}

The most important criteria for success involving the recipient site is adequacy of bone support. There must be sufficient alveolar bone support in all dimensions with adequate attached keratinized tissue to allow for stabilization of the transplanted tooth. In addition, the recipient site should be free from acute infection and chronic inflammation ${ }^{12}$.

\section{Donor tooth criteria:}

The donor tooth should be in such a position that extraction will be as atraumatic as possible. Abnormal root morphology, which makes tooth removal exceedingly difficult and may involve tooth sectioning, is contraindicated for this surgery. Teeth with either open or closed apices may be donors; however, the most predictable results are obtained with teeth having between one-half to two-thirds completed root development. Surgical manipulation of teeth with less than one-half root formation may be too traumatic and could compromise further root development ${ }^{1,6,7,9,12-16}$, stunting maturation or altering morphology. When root development is greater than two-thirds, the increased length may cause encroachment on vital structures such as the maxillary sinus or the inferior alveolar nerve ${ }^{13}$. Furthermore, a tooth with complete or near complete root formation will generally require root canal therapy, while a tooth with an open apex will remain vital and should continue root development after transplantation. In the latter case, successful transplantation without the need for further endodontic therapy is usually seen.

\section{Case report:}

A 28-year-old female came to the department of Conservative Dentistry and Endodontics, Faculty of
Dentistry, BSMMU with the complaints of mild pain and discomfort in the anterior region of the lower jaw. On clinical examination she had retained deciduous canine on both sides of lower jaw. On palpation, she felt slight pain on the lower anterior region. Radiological examination reveals ectopic position of both permanent canines. The canines were vertically impacted near the root of the central incisors (Fig.-1, Fig.-13).

After discussion of all the treatment options with the patient and her guardian, it was decided to extract the retained deciduous canine (Figs.-6a, 6b) and to transplant the impacted permanent canine in their proper position (Fig.-8).

\section{Surgical procedure:}

With all aseptic precaution, the impacted right mandibular canine was gently extracted out under local anaesthesia (Fig.-2). Extra oral endodontic treatment was carried out (Figs.-5a, b, c, d) while the retained deciduous tooth on the same side undergone extraction (Figs.-4, 6a, b). The extraction site was pressed with gauze piece to maintain haemostasis (Fig.- 4). After extraction of the deciduous tooth, the depth and width of the socket was modified. Care was taken not to extend lengthy extra oral time.

As soon as the socket was prepared the tooth was transplanted in the prepared socket and fixation was done by functional splint (Fig.-10). A post-operative radiograph was taken (Fig.- 14).

Antibiotic (cap. Sefrad $500 \mathrm{mg}$ eight hourly for seven days) was prescribed pre- and post-operatively, The patient was instructed to take soft diet, maintenance of oral hygiene and not to use the tooth for few weeks, and advised to come after two weeks. On the next appointment the transplanted tooth was examined clinically but there was no pain, discomfort and mobility, the tooth was firm in position and the radiograph revealed no signs of developing pathology (Figs.-11, 14). The splint was removed after four weeks and the patient was advised to come for the follow-up visit after three months, six months, then yearly for five years (Fig.-15). 


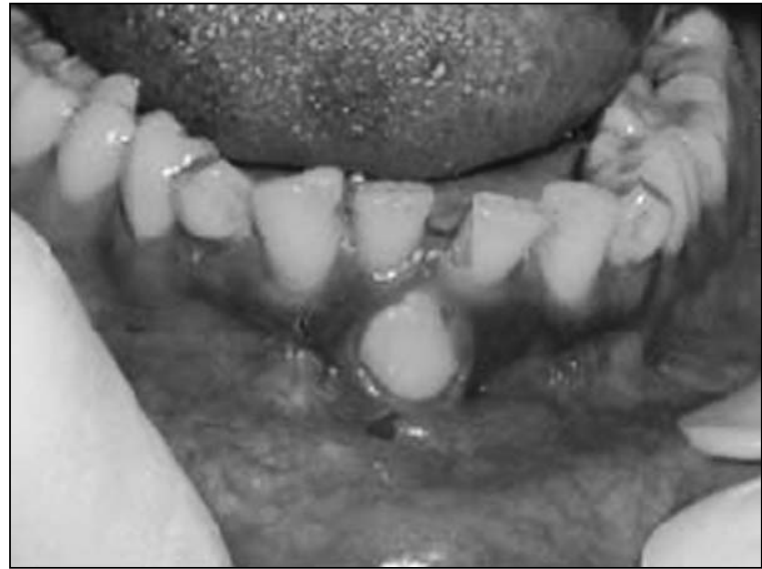

Fig.-1: Pre-operative view of Impacted Canine in ectopic position.

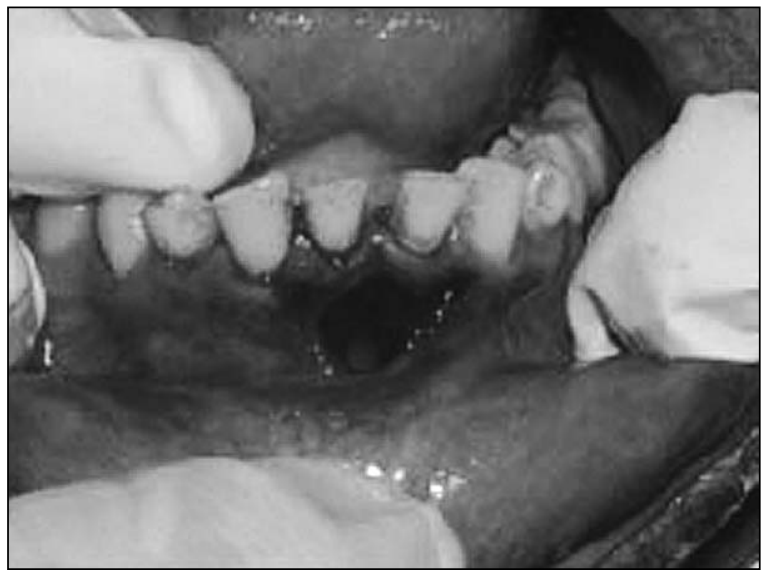

Fig.-3: Open socket after extraction of Impacted canine.

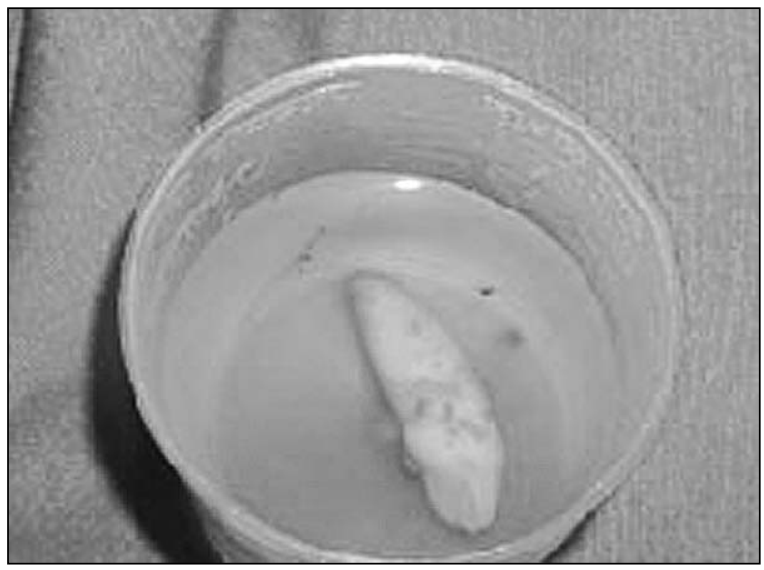

Fig.-5 (a): Extraoral endodontic preparation of extracted impacted canine.

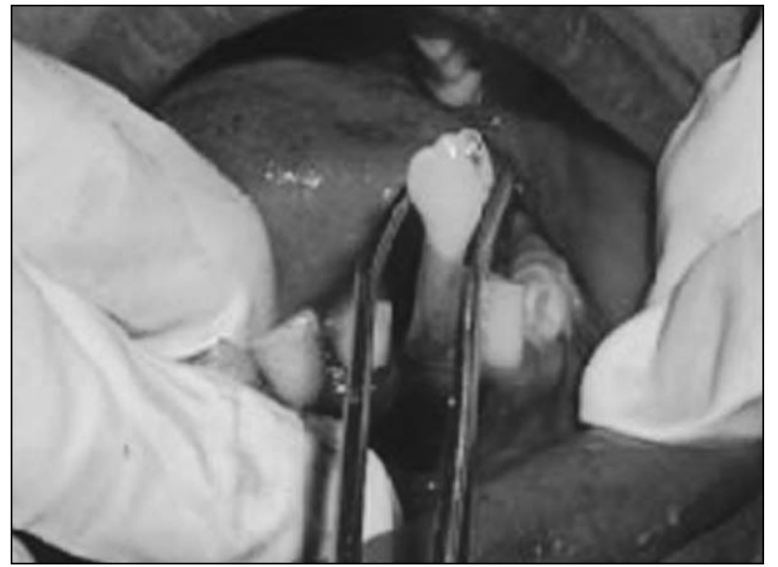

Fig.-2: Extraction of Impacted anine.

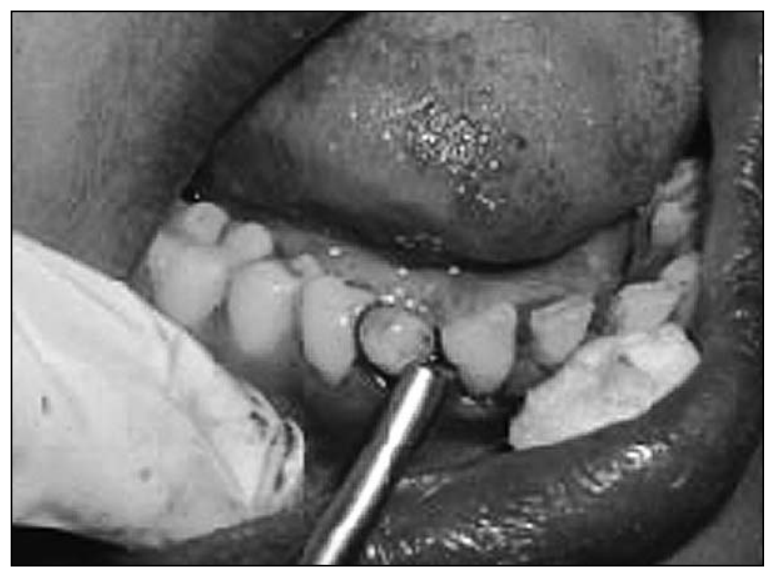

Fig.-4: Haemostasis of open socket.

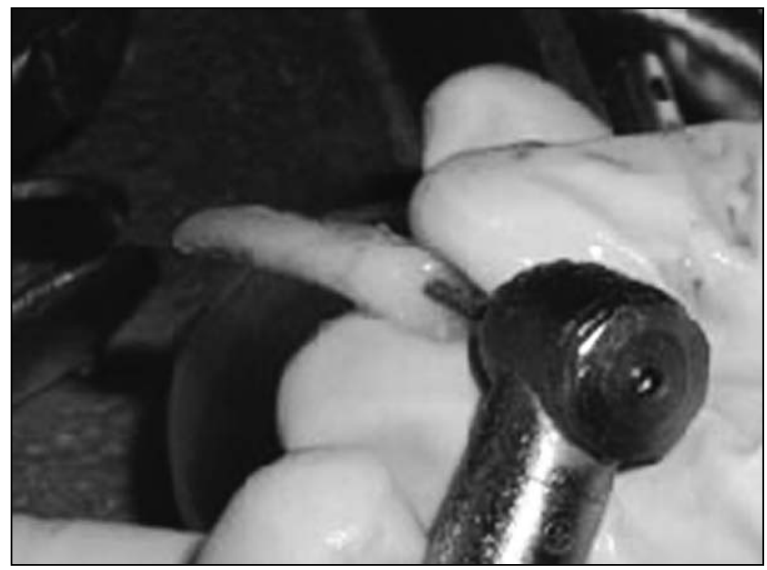

Fig.-5 (b): Extraoral endodontic preparation of extracted impacted canine. 


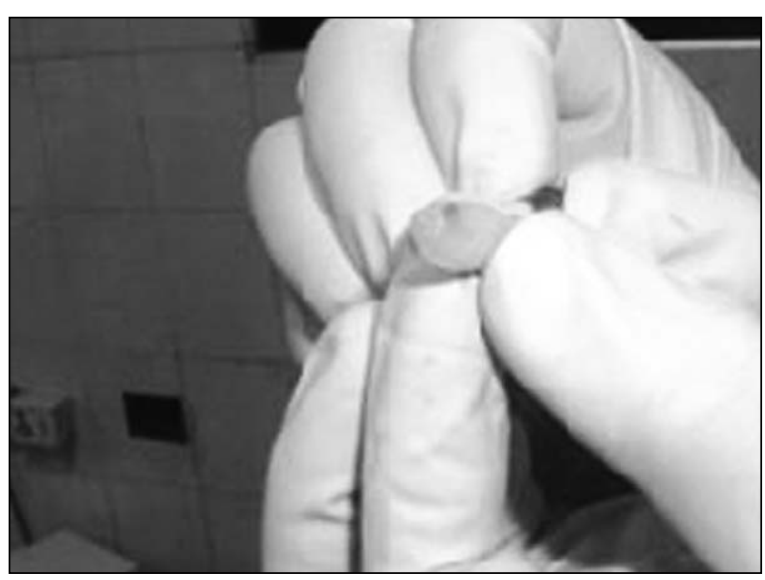

Fig.-5 (c): Extraoral endodontic preparation of extracted impacted canine.

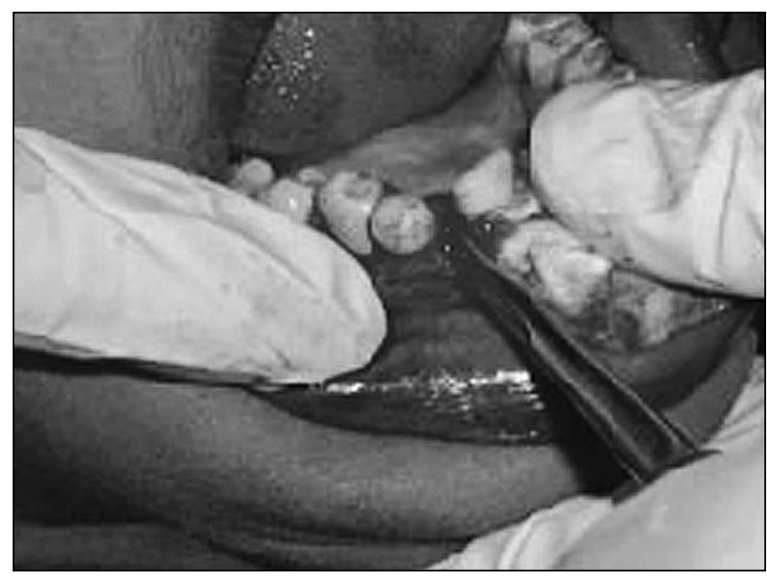

Fig.-6 (a): Removal of retained deciduous canine and socket preparation.

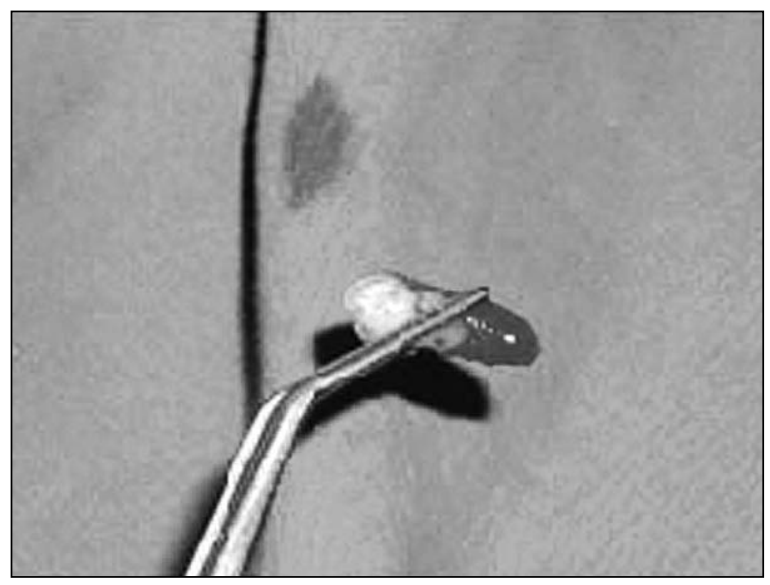

Fig.-7: Removed retained deciduous canine from the socket.

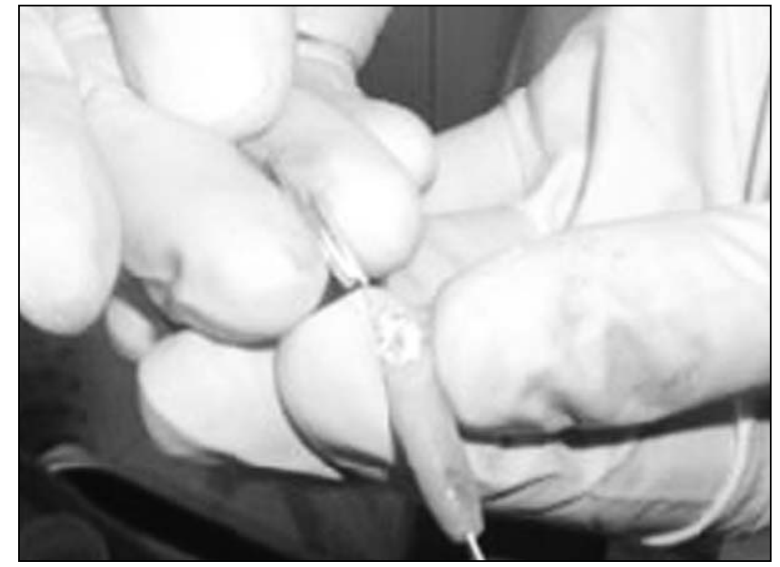

Fig.-5 (d): Extraoral endodontic preparation of extracted impacted canine.

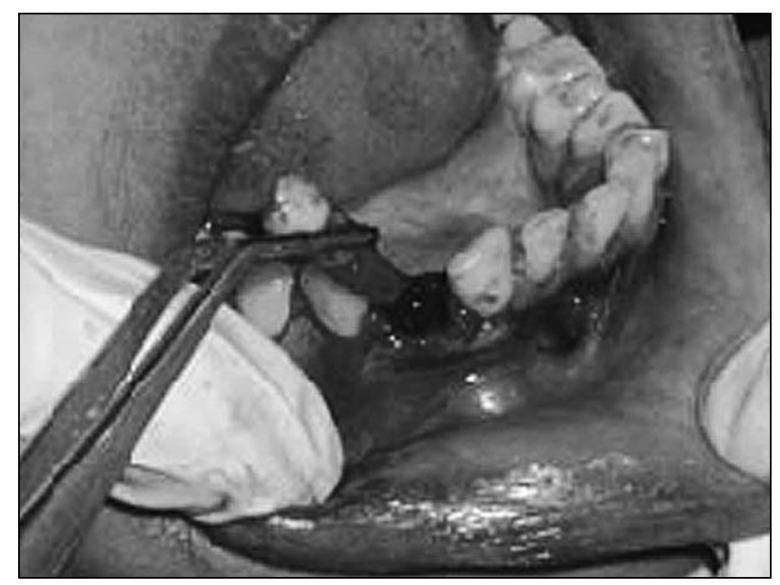

Fig.-6 (b): Removal of retained deciduous canine and socket preparation.

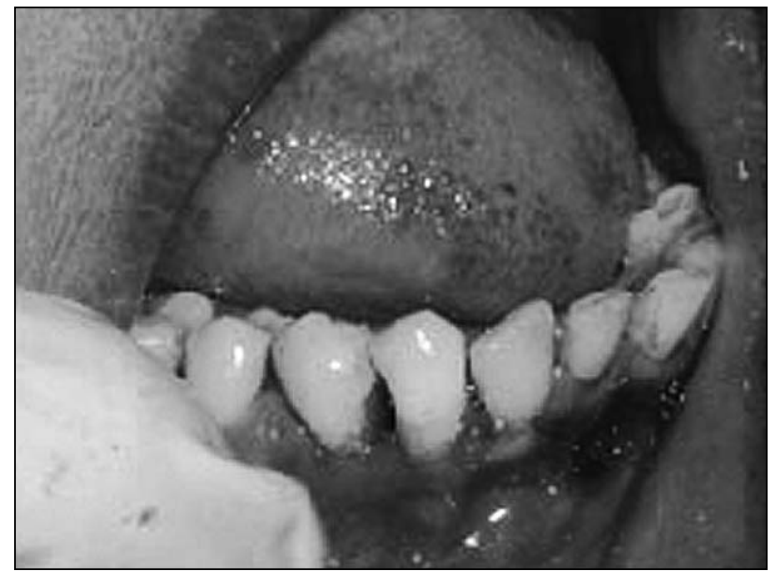

Fig.-8: Immediately after transplantation. 


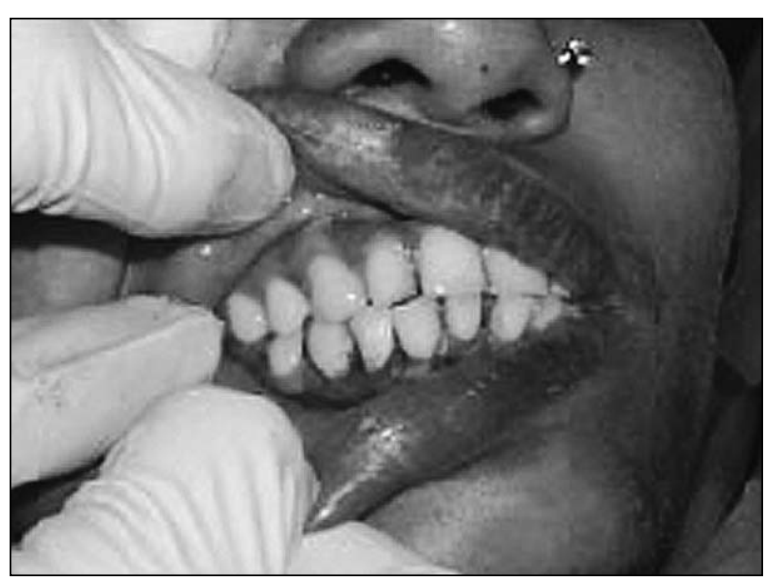

Fig.-9: Tooth in occlusion.

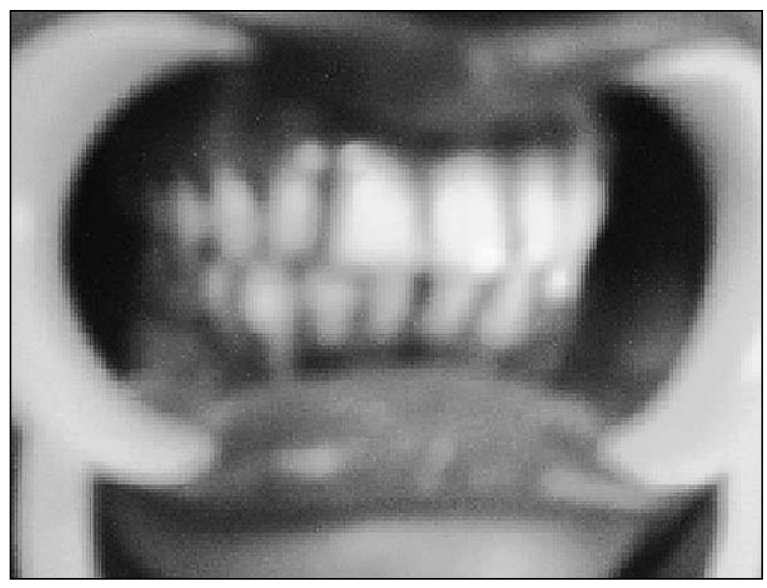

Fig.-11: Follow-up.

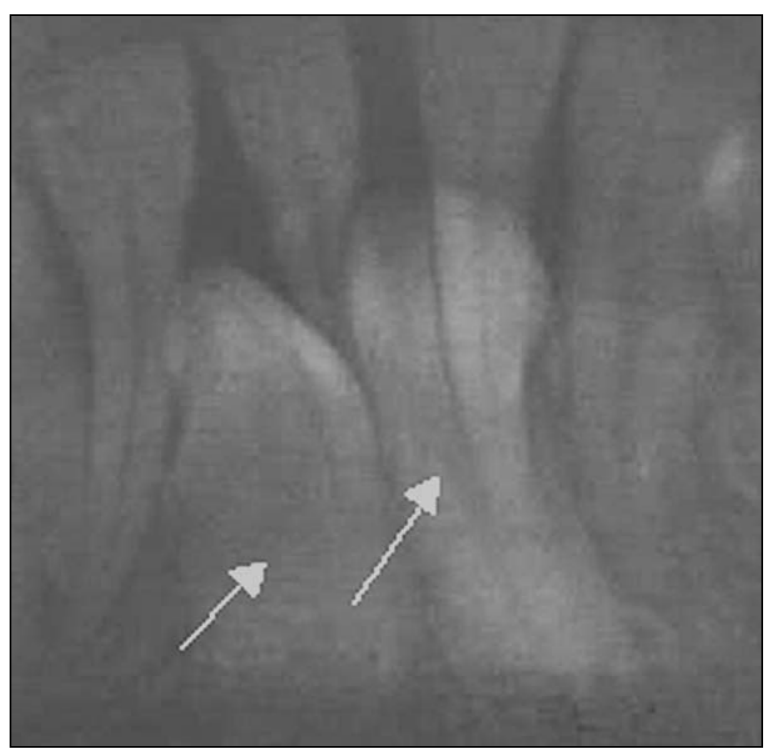

Fig.-13: Pre-operative radiograph showing impacted permanent canines.

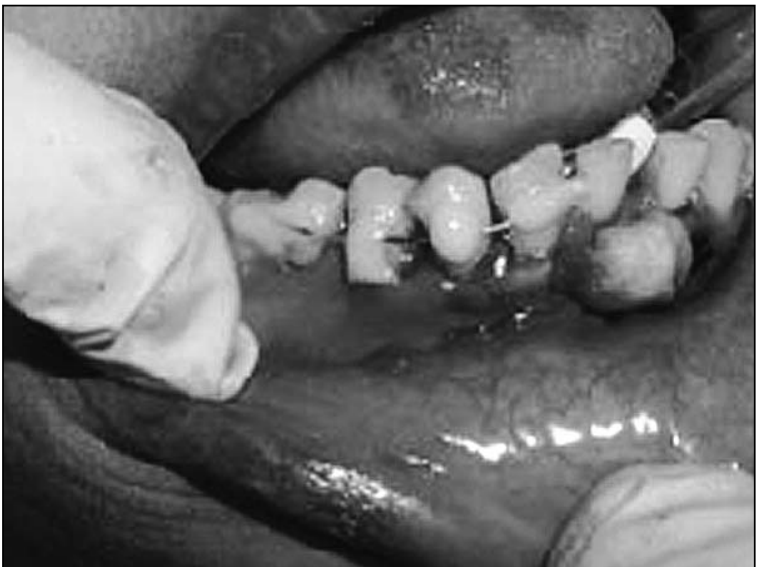

Fig.-10: After functional splint.

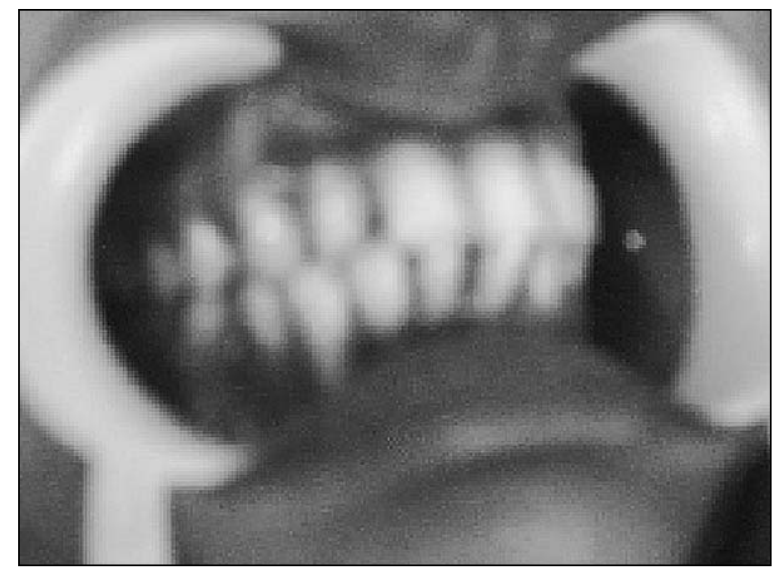

Fig.-12: After removal of splint.

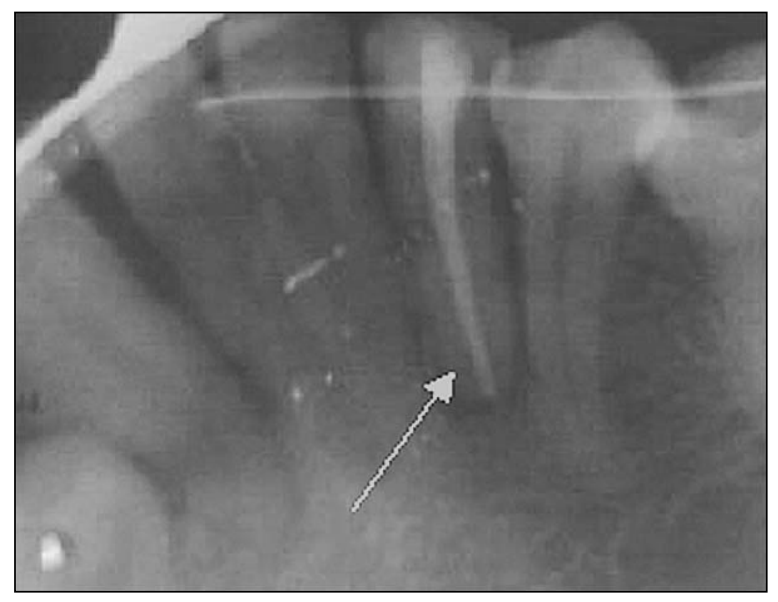

Fig.-14: Radiograph immediately after treatment 


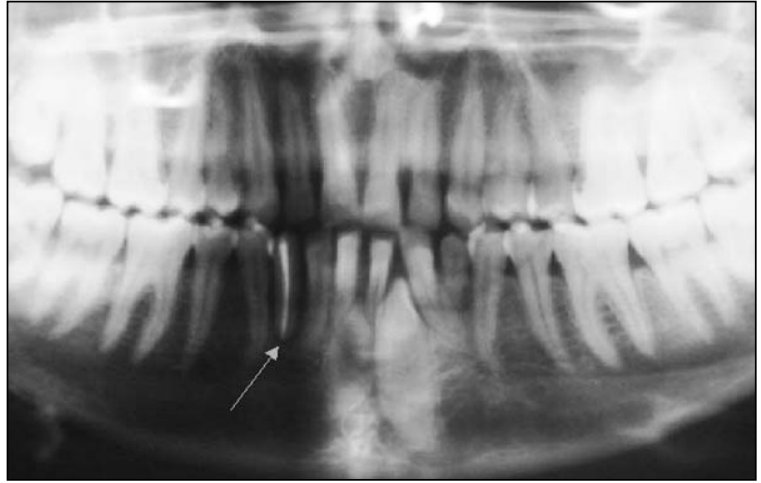

Fig.-15: Post-operative radiograph of transplanted canine in correct occlusion.

\section{Discussion:}

This is the first case report of autogenous tooth transplantation in Bangladesh. The case came out successful after periodic, immediate and long -term follow-up up to $1 \frac{1}{2}$ years. The available literature reports excellent success rates following tooth transplantation when the appropriate protocol is followed. Andreasen ${ }^{5}$ found $95 \%$ and $98 \%$ long-term survival rates for incomplete and complete root formation of 370 transplanted premolars observed over 13 years. Lundberg and Isaksson ${ }^{6}$ had success in $94 \%$ and $84 \%$ of cases for open and closed apices respectively in 278 auto transplanted teeth over five years. Kugelberg ${ }^{7}$ achieved success rates of $96 \%$ and $82 \%$ for 45 immature and mature teeth transplanted into the upper incisor region over four years. Cohen ${ }^{1}$ showed success in the ranges of $98-99 \%$ over five years and 80 $87 \%$ over 10 years with transplanted anterior teeth with closed apices. Nethander ${ }^{4}$ found 5 -year success rates of over $90 \%$ for 68 mature teeth transplanted with a 2 -stage technique. Josefsson ${ }^{8}$ found 4 -year success rates of $92 \%$ and $82 \%$ respectively for premolars with incomplete and complete root formation.

These consistently high success rates are a contrast to the variable results reported in many older studies. Schwartz and others ${ }^{16}$ showed success rates of only $76.2 \%$ at 5 years and $59.6 \%$ at 10 years. Similarly, Pogrel found that his success rate for 416 autotransplanted teeth was $72 \%$. However, other investigators of that era had more positive results ${ }^{13}$. Kristerson, for example, obtained a success rate of 93\% when 100 autotransplanted premolars were observed for a mean of 6.3 years $^{11}$.
The factors that lead to success have been extensively investigated. The most significant determinant for survival of the transplant is the continued vitality of the periodontal membrane. In cases where the periodontal ligament is traumatized during transplantation, external root resorption and ankylosis is often noted ${ }^{1,13}$. Schwartz ${ }^{16}$ tried to link the loss of the graft to specific prognostic factors and found that success rates were highest when donor teeth were premolars, had one-half to two-thirds root development, and experienced minimal trauma and limited extraoral time during surgery. The experience of the surgeon also affects the success because this procedure is technique-sensitive.

Although retention of the tooth and restoration of the edentulous space is the desired outcome for patients, more specific parameters have been used to measure the health of the surviving transplant. These parameters include marginal periodontal attachment, mobility, pain, root resorption, root development, sensitivity to percussion, gingival pocket depth, presence of gingivitis, and presence of fistulae $e^{4,19,20}$. However, these studies are difficult to compare because each used different measures to determine success.

The most common cause of failure of the autotransplant is chronic root resorption ${ }^{15}$. More specifically, the causes of tooth loss following transplantation from most common to least common are inflammatory resorption, replacement resorption (ankylosis), marginal periodontitis, apical periodontitis, caries, and trauma ${ }^{16}$. Inflammatory resorption may become evident after three or four weeks, while replacement resorption may not become evident until three or four months after transplantation. The incidence of both types of resorption can be decreased with atraumatic extraction of the donor tooth and immediate transfer to the recipient site to minimize the risk of injury to the periodontal ligament ${ }^{1}$.

Recent studies clearly demonstrate that autotransplantation of teeth is as successful as endosseous dental implant placement. Minimum acceptable success rates for endosseous titanium dental implants are $85 \%$ after five years and $80 \%$ after 10 years $^{21}$. For younger patients, 
autotransplantation may also be considered as a temporary measure. The transplant can replace missing teeth to ensure preservation of bone until growth has ceased and then, if necessary, the patient can become a candidate for implants ${ }^{22}$.

Although autotransplantation has not been established as a traditional means of replacing a missing tooth, the procedure warrants more consideration. With appropriate patient selection and presence of a suitable donor tooth and recipient site, autogenous transplantation should be considered as a viable option for treatment of an edentulous space.

\section{References}

1. Cohen AS, Shen TC, Pogrel MA. Transplanting teeth successfully: autografts and allografts that work. JADA 1995; 126: 481-5.

2. Leffingwell CM. Autogenous tooth transplantation: a therapeutic alternative. Dent Surv 1980; 56: 22-3, 26.

3. Hale ML. Autogenous transplants. Oral Surg Oral Med Oral Pathol 1956; 9: 76-83.

4. Nethander G. Periodontal conditions of teeth autogenously transplanted by a two-stage technique. J Periodontal Res 1994; 29: 250-8.

5. Andreasen JO, Paulsen HU, Yu Z, Bayer T, Schwartz O. A long-term study of 370 autotransplanted premolars. Part II. Tooth survival and pulp healing subsequent to transplantation. Eur J Orthod 1990; 12: 14-24.

6. Lundberg T, Isaksson S. A clinical follow-up study of 278 autotransplanted teeth. Br J Oral Maxillofac Surg 1996; 34 : 181-5.

7. Kugelberg R, Tegsjo U, Malmgren O. Autotransplantation of 45 teeth to the upper incisor region in adolescents. Swed Dent J 1994; 18: 165-72.

8. Josefsson E, Brattstrom V, Tegsjo U, Valerius-Olsson H. Treatment of lower second premolar agenesis by autotransplantation: four-year evaluation of eighty patients. Acta Odontol Scand 1999; 57: 111-5.

9. Kahnberg KE. Autotransplantation of teeth: indications for transplantation with a follow-up of 51 cases. Int $\mathrm{J}$ Oral Maxillofac Surg 1987; 16: 577-85.
10. Tegsjo U, Valerius-Olsson H, Frykholm A, Olgart K. Clinical evaluation of intra-alveolar transplantation of teeth with cervical root fractures. Swed Dent J 1987; 11: 235-50.

11. Kristerson L, Lagerstrom L. Autotransplantation of teeth in cases with agenesis or traumatic loss of maxillary incisors. Eur J Orthod 1991; 13: 486-92.

12. Northway WM, Konigsberg S. Autogenic tooth transplantation: the "state of the art". Am J Orthod 1980; 77: 146-62.

13. Pogrel MA. Evaluation of over 400 autogenous tooth transplants. J Oral Maxillofac Surg 1987; 45: 205-11.

14. Akiyama Y, Fukuda H, Hashimoto K. A clinical and radiographic study of 25 autotransplanted third molars. J Oral Rehabil 1988; 25: 640-4.

15. Robinson PJ, Grossman LI. Tooth Transplantation. In: Robinson PJ, Guernsey LJ, (editors) Clinical Transplantation in Dental Specialties. St. Louis: C.V. Mosby Co.; 1980. pp77-88

16. Schwartz O, Bergmann P, Klausen B. Autotransplantation of human teeth: a life-table analysis of prognostic factors. Int $\mathrm{J}$ Oral Surg 1985; 14: 245-58.

17. Andreasen JO, Paulsen HU, Yu Z, Ahlquist R, Bayer T, Schwartz O. A long-term study of 370 autotransplanted premolars. Part I. Surgical procedures and standardized techniques for monitoring healing. Eur J Orthod 1990; 12: 3-13.

18. Tsukiboshi M. Autogenous tooth transplantation: a reevaluation. Int J Periodontics Restorative Dent 1993; 13: $120-49$.

19. Andreasen JO, Paulsen HU, Yu Z, Schwartz O. A long-term study of 370 autotransplanted premolars. Part III. Periodontal healing subsequent to transplantation. Eur J Orthod 1990; 12: 25-37.

20. Andreasen JO, Paulsen HU, Yu Z, Bayer T. A long-term study of 370 autotransplanted premolars. Part IV. Root development subsequent to transplantation. Eur J Orthod 1990; 12: 38-50.

21. Smith DE, Zarb GA. Criteria for success of osseointegrated endosseous implants. J Prosthet Dent 1989; 62: 567-72.

22. Thomas S, Turner SR, Sandy R. Autotransplantation of teeth: is there a role? Br J Orthod 1998; 25: 275-82. 